\title{
Hospital volunteerism as human resource solution: Motivation for both volunteers and the public health sector
}

\begin{tabular}{|c|c|}
\hline \multicolumn{2}{|c|}{$\begin{array}{l}\text { Authors: } \\
\text { Guinevere M. Lourens }{ }^{1,2} \\
\text { Danielle K. Daniels-Felix }{ }^{1}\end{array}$} \\
\hline \multicolumn{2}{|c|}{$\begin{array}{l}\text { Affiliations: } \\
{ }^{1} \text { Ukwanda Centre for } \\
\text { Rural Health, Stellenbosch } \\
\text { University, South Africa }\end{array}$} \\
\hline \multicolumn{2}{|c|}{$\begin{array}{l}{ }^{2} \text { Department of Nursing and } \\
\text { Midwifery, Stellenbosch } \\
\text { University, South Africa }\end{array}$} \\
\hline \multicolumn{2}{|c|}{$\begin{array}{l}\text { Corresponding author: } \\
\text { Guinevere Lourens, } \\
\text { guin@sun.ac.za }\end{array}$} \\
\hline \multicolumn{2}{|c|}{$\begin{array}{l}\text { Dates: } \\
\text { Received: } 21 \text { Apr. } 2016 \\
\text { Accepted: } 25 \text { May } 2017 \\
\text { Published: } 15 \text { Aug. } 2017\end{array}$} \\
\hline \multicolumn{2}{|c|}{$\begin{array}{l}\text { How to cite this article: } \\
\text { Lourens, G.M., \& Daniels- } \\
\text { Felix, D.K. (2017). Hospital } \\
\text { volunteerism as human } \\
\text { resource solution: Motivation } \\
\text { for both volunteers and the } \\
\text { public health sector. SA } \\
\text { Journal of Human Resource } \\
\text { Management/SA Tydskrif vir } \\
\text { Menslikehulpbronbestuur, } \\
\text { 15(0), a813. https://doi. } \\
\text { org/10.4102/sajhrm. } \\
\text { v15i0.813 }\end{array}$} \\
\hline \multicolumn{2}{|c|}{$\begin{array}{l}\text { Copyright: } \\
\text { (C) 2017. The Authors. } \\
\text { Licensee: AOSIS. This } \\
\text { is licensed under the } \\
\text { Creative Commons } \\
\text { Attribution License. }\end{array}$} \\
\hline \multicolumn{2}{|l|}{ Read online: } \\
\hline 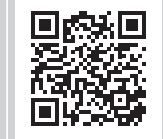 & $\begin{array}{l}\text { Scan this QR } \\
\text { code with your } \\
\text { smart phone or } \\
\text { mobile device } \\
\text { to read online. }\end{array}$ \\
\hline
\end{tabular}

Background: A volunteer programme with 50 registered volunteers was established in 2007 at a secondary-level public, semi-rural regional hospital in the Cape Winelands, South Africa. This was a rapid response to the extensive renovations and system changes brought about by the hospital revitalisation initiated in 2006 and the resultant expanded services, which required additional human resources. This study describes the hospital volunteer programme and provides hospital administrators with practical planning guidance for hospital volunteer programme implementation.

Purpose: The purpose of this study is to (1) describe the outcomes of the hospital volunteer programme implementation intervention and (2) to make sound recommendations for volunteer programme implementation.

Methodology and approach: A qualitative case-study methodology was employed using purposive sampling as a technique. Participants were recruited from a public hospital in the Western Cape. A case-study design was applied to explore the hospital volunteer programme implementation. In-depth interviews and a focus group discussion with thematic content analysis of transcripts as well as document reviews were conducted to conclude the study during 2015. The key participants were individually interviewed and included two members of the hospital management, two volunteers and one volunteer coordinator. A focus group discussion consisting of three volunteers was also conducted.

Findings: The findings of this study indicate that a volunteer programme can meet needs and be a motivational force for both the individual volunteer and the organisation. However, it requires co-ordination and some secure funding to remain sustainable. Such a programme holds huge benefits in terms of human resource supplementation, organisational development, as well as the possibility of gainful employment for the previously unemployed.

Practical implications: In practice, a health service contemplating a volunteer programme should develop criteria for recruitment and selection of volunteers, accompanied by the necessary documentation for applications. A coordinator of the volunteer service needs to be identified. Volunteers will need to be orientated, given access to in-service training and supervised. Consideration needs to be given to risk management of vicarious liability by developing a code of conduct, clear roles and responsibilities, managing staff and volunteer relationships and providing emergency care for injuries while on duty as a volunteer.

\section{Introduction}

Volunteers play a crucial role within the health care system (Prabhu, Hanley \& Kearney, 2008, p. 265). There is scope to further the promise of possibility and opportunity for both the volunteers involved and the hospital in which a volunteer programme is established. Hotchkiss, Fottler and Unruh (2009, p. 127) found a positive relationship between volunteerism and hospital cost saving but suggested a need for further research. The exploration of the sensitive issue of the relationship between volunteer and paid labour is also an area for future research (Handy, Mook \& Quarter, 2008, p. 16), which could have implications for volunteerism policy, as well as public leadership.

Penner (2002, p. 448) defined volunteerism as 'long-term, planned prosocial behaviour that benefits strangers and occurs within an organizational setting. Volunteerism has four salient attributes: longevity, planfulness, non-obligatory helping and an organizational context'. Hotchkiss, Unruh and Fottler (2014, p. 15) call for health care executives to share best practices in volunteer recruitment, screening, orientation, training, policies, service guidelines and risk management plans in formalisation of volunteer programmes. 
The National Department of Health of South Africa implemented a Hospital Revitalisation Grant to modernise and transform the infrastructure and health technology of public hospitals and improve the access to health care as well as quality of care. A secondary-level, semi-rural, public regional hospital in the Cape Winelands was entered into the Hospital Revitalisation Programme (HRP) in May 2006 and reached practical completion on 23 March 2012.

Hospital revitalisation is an organisational development intervention in its own right as it brings about organisationwide changes in the physical surroundings, workflow and modernised technology requiring skills training. The expanded services make way for human resource expansion. However, the expanded services were not well aligned to the existing staff establishment, and funding constraints prevented filling of required posts.

The management at this hospital implemented a volunteer programme in 2007 as one of the planned interventions to cope with the rapid change brought about by revitalisation and the expanded services as a result of these renovations. The hospital board initiated a volunteer programme whereby 50 individuals volunteered to assist by working in the pharmacy, linen bank, porter service and cleaning team, or to be part of the Pamper Team, a group of volunteers doing hair and nail care. Although the number of volunteers on any given day may fluctuate, the hospital has subsequently retained this number of a maximum of 50 volunteers, which can be accommodated daily in the volunteer service.

Following this opportunity to volunteer, there have been numerous success stories arising from this programme. The advantage of being volunteers at a hospital when a position becomes vacant is that they have a competitive edge on application and during the interview over other candidates. However, the literature should culminate on success stories of volunteers at hospitals such as the case illustrated of the hospital in this study.

The literature search revealed many hospitals providing case studies on the success of their volunteer programmes, but they have used 'volunteer' as a broader term meaning an individual who provides work for no profit. It should be noted that there are different categories of volunteers: professional volunteers (retired nurses and doctors and allied health professionals) and non-professional volunteers (housekeepers, cleaners, porters, etc.). Most of the literature focuses on professional volunteers. There is a scarcity of literature concentrating on non-professional volunteers in hospitals, who have secured jobs as a result of their nonprofit labour experience.

This area of volunteerism has been under-researched because volunteerism in health care organisations in a broader context usually involves patient care and administration. In this particular study, volunteerism involves working in various service support departments such as pharmacy, medical records, kitchen, linen bank, porter service and cleaning and Pamper teams. The volunteers in this study do not assist with caring for the physical health of the patients.

Volunteers assist an organisation to 'increase capacity and resources within the health services' (Jones, 2004, p. 5). Connors (2011, p. 117) concurs that volunteers enable expansion of service despite budgetary limitations. International studies on volunteerism indicate that volunteers perform tasks in different areas such as transporting patients, assisting with clerical duties and providing information. A study conducted by Jones (2004) indicated that $60 \%$ of the participants within the health setting found that volunteers improved services by supporting staff and adding value to the services being rendered. According to Handy and Srinivasan (2004), volunteers are assigned to: escort patients on outings, provide companionship and support to patients, assist with recreational and social programmes, help with shopping and doing errands, and accompany patients from one facility to another and administrative work. However, in Japanese hospitals, volunteer activities were related to 'recreation, conversation partners, music and entertainment, wheelchair pushing and helping with administration' (Aragaki, Saito, Takahashi \& Kai, 2007). The dynamics of volunteer activities show how volunteer roles are emerging through closer contact with the patients and how volunteer positions have evolved over the years.

According to Connors (2011), all volunteer involvement generates risks. Ellis (2012) suggests that risk assessment is always valid, as an organisation should want to keep all participants safe.

Hotchkiss et al. (2014) indicate a gap within volunteerism theory and mention that the types of positions in which volunteers are used should be measured in future research. Because this area is under-researched, it is advisable that studies are done on non-professional volunteers in hospitals. Studies should evaluate success stories of non-professional volunteer programmes in other hospitals and examine whether there are rewards or benefits that go along with being a volunteer.

\section{Research aim or purpose}

This study aimed to provide a description of a hospital volunteer programme, which will contribute to the body of knowledge on hospital volunteer programme implementation. The public health sector and role-players in public health management stand to benefit from this research.

\section{Theoretical framework}

The conceptual framework in qualitative research utilises concepts from existing theories and relates the findings to these. Theories help to understand the phenomenon and incorporate our understanding of the setting, people, processes and the interrelationships (Maxwell, 2012, pp. 85-87). 
Motivational theories build on the extrinsic conditions which stimulate certain behaviours and the intrinsic responses sustained by sources of energy or motives which drive action (Jooste, 2009, p. 69). The humanistic content theories of motivation focus on inner needs that motivate behaviour and are associated with thinkers such as Maslow, Alderfer, Atkinson, Herzberg, McClelland and McGregor. Maslow's theory of motivation was helpful in understanding the motives served by volunteerism. The Maslow (1954) motivation theory is one of the best known, influential theories on workplace motivation, which suggests that humans have a hierarchy of needs and that when basic psychological and physical needs are met, the focus on safety, a sense of belonging, esteem and self-actualisation follows.

Blanchard (2006, p. 31) found that motivations to volunteer in a hospital are complex. Volunteers can be sustained by non-altruistic motives of the social benefits and upskilling for personal enhancement. Besides personal fulfilment, generosity was also found to be influential in volunteering. Other studies highlight social rewards of volunteering and the draw of personal and indirect economic rewards.

\section{Methods}

A case-study design with a qualitative approach was utilised for this study. In case-study research, all evidence is collated in data collection and qualitative methods are regarded as primary. The case-study design involves an intensive exploration of a single unit of study (Bowling, 2009, p. 434) such as the hospital being studied and was therefore selected as most suited to exploring this public secondary regional hospital institution volunteer programme.

The goal of qualitative studies is not to generalise but to understand the processes and meanings for the specific setting. The guiding principle in a qualitative study is selecting the setting and individual or participants who are most accessible and conducive to gaining the understanding on what you want to know (Maxwell, 2012, pp. 94-95).

Qualitative content analysis with thematic coding was applied to the data set.

The interviews took place in private office spaces and the focus group in the boardroom of the hospital, which was most convenient for the participants. Five participants from the hospital were asked to participate in individual interviews and another three in a focus group. The individual interviewees included two members of hospital management, two volunteers and one volunteer coordinator. The focus group consisted of three volunteers. A purposive sampling technique was used and the eight participants joined in the study. The interview schedule and focus group consisted of four questions and provided information regarding the participant's involvement and experience of the volunteer programme, the challenges experienced and their recommendations going forward. With the consent of the participants, the interviews were recorded and transcribed verbatim. The interviews and focus groups were conducted face to face and did not exceed an hour.

The qualitative methodology adopted included the following data collection methods: individual interviews and a focus group with purposively sampled key participants and the analysis of documents pertaining to the volunteer implementation programme. Although the in-depth interviews and the focus group were the primary source of data collection, reviewing documents was also used to build a description of the case. The following documents were reviewed: (1) volunteer recruitment document, (2) application documents developed, (3) the volunteer register, (4) attendance register and (5) statistics on volunteer training and those gainfully employed at the hospital or other placements during the course of revitalisation. The different sources of data enabled multi-method data collection, which serves to triangulate data (Ross, 2012, pp. 134-135).

\section{Ethical considerations}

Ethics approval for the study was obtained from the Human Research Ethics Committee of Stellenbosch University.

\section{Findings}

In May 2007, a volunteer programme was established by employing a part-time coordinator. She had to coordinate the volunteers who wanted to assist the hospital for $4 \mathrm{~h}$ daily, initially on week days only. She was mentored by an experienced manager in the Radiology Department. She initially handled a team of 30 volunteers daily and was assisted by the whole of the Radiology Department, which adopted this campaign and assisted her whenever assistance was needed or when she was on leave or off sick.

The programme was mainly advertised by word of mouth and soon the number of volunteers had to be restricted to 50 , which could be handled on a daily basis. The volunteers included semi-skilled and unskilled people. Volunteers worked as cleaners, porters, administrative clerks, medical records clerks, stores assistants and linen assistants. There was also the establishment of the Pampering Team, which renders hair and nail care to clients admitted to hospital in a state of neglect or those far from home with no relatives close by. The necessities such as a trolley with stationery, shampoo, soap, and hair and nail equipment for this programme were funded by the Hospital Facility Board.

With the introduction of Clinicom (a new client record database) to the hospital, new human resource challenges emerged, and dedicated volunteers were trained to assist some of the service departments with this added work load. The programme was extended on request by the emergency centre to include having volunteers on duty over weekends to assist the patients and their family or as escorts in the waiting rooms by handing out beverages for those waiting for long periods of time. Volunteers also assist the patients by asking the nursing staff about waiting times. Later volunteers 
were utilised as queue marshals in the busy outpatients department.

The one aspect regarded by informants as the main success of the programme was the number of volunteers who were subsequently permanently employed, both at this hospital and at other public health sector institutions or the private sector. By the conclusion of this study, seven people were employed as porters, eight people as general assistants, seven people as clerks, five people in the food service department and one person in the linen bank. Six people were employed as pharmacy assistants, two at this institution and the others at other institutions. There are also many volunteers working as paid locums, 6 in the pharmacy, 20 as general assistants and 1 as a porter.

The five participants were interviewed individually, and three members joined in a focus group discussion on the programme experience, challenges and recommendations. Those involved in the programme at the hospital expressed pride in their contribution, to give the volunteers a chance to gain experience and provide them with testimonials via the coordinator when needed at the end of their volunteer time. Two main themes emerged, namely economic and altruistic drivers. Four sub-themes emerged from the participants' responses and the quotes are presented below. These themes are displayed diagrammatically in Figure 1. Responses given in Afrikaans have been translated into English and are indicated by square brackets. Each theme is explained and participant quotes from the interviews and focus group discussion are added to illuminate the meaning of each theme.

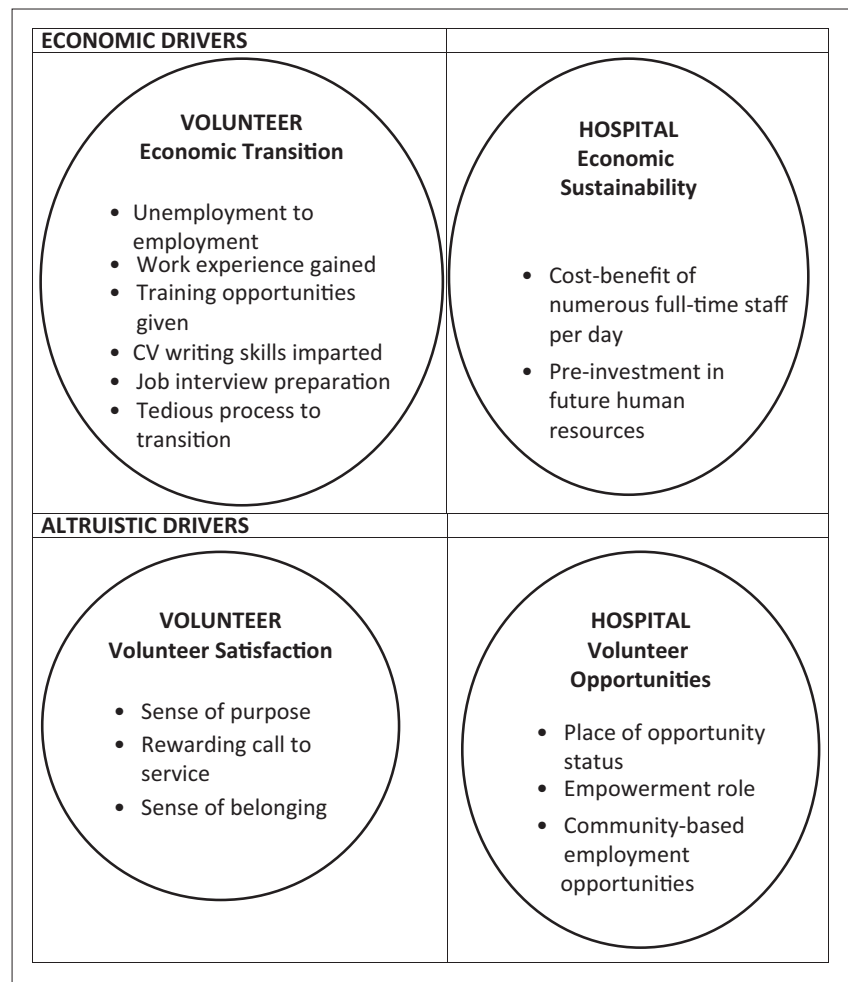

FIGURE 1: Economic and altruistic drivers in volunteer programme.

\section{Economic transition}

For the volunteers, the opportunity to be a volunteer in this programme led to some form of economic transition, albeit a tedious process. For some volunteers, it took many years of volunteering before they realised this transition.

The transition was moving from unemployment to gainful employment, either in positions at the hospital, other health facilities or as contract workers for locum agencies. Volunteers were asked to register with locum agencies and were given preference when paid locum jobs became available. Volunteers were assisted with on-the-job training, gaining work experience, CV-writing skills and job interview skills, all of which were seen as contributing factors towards making this transition. Informants said that it was the power of this possibility which kept them in the programme so long.

The comments included:

Volunteerism ... is a foot in the door and you get experience ... The volunteers got opportunities to earn money in locum positions; based on the experience they gained. (Respondent 2, Female, Volunteer)

I can only say to those who want to volunteer, only good can come from volunteering. What you sow, you will reap. You need to be prepared to plough and your heart needs to be right. (Respondent 4, Female, Volunteer)

\section{Economic sustainability}

For the hospital, the economic driver for the volunteer programme was the economic benefits it held. The costbenefit of the volunteer programme totalled the equivalent of 14 full-time staff members in the hours volunteered in various departments. The 'pre-investment' in volunteers in terms of on-the-job training paid off when those volunteers successfully applied for vacant posts. The transition into the job was relatively seamless as pre-knowledge existed about the position and the organisational environment.

The following participant had calculated that the hours put in by volunteers equated to 14 full-time staff members:

Stats show we recruit the equivalent of 14 full-time workers at the hospital through the volunteer programme. (Respondent 5, Male, Hospital Management)

Prior investment in people took place and the fact that the volunteers had already been trained in their jobs means that the investments pays off when the person starts working and they already have some skills. (Respondent 5, Male, Hospital Management)

\section{Volunteer satisfaction}

For the volunteers, satisfaction came from having a sense of purpose on a daily basis. As they become known at the hospital, they developed a sense of belonging. They described the personal satisfaction of being 'seen', and noticed by others. They acknowledged that it was sometimes a difficult environment with so many diverse people, but found it purposeful. 
The comments included:

I got purpose ... and I feel that I belong ... I was motivated and felt acknowledged which makes you feel that you belong. (Respondent 3, Male, Volunteer)

We are in a people business. People are the essence. It is give and take. It is not a high profile job, but purposeful. Being out there is difficult. (Respondent 3, Male, Volunteer)

I want to add that as a volunteer, you introduce yourself to the staff. They get used to you and it is one of the advantages. If you enter the building, the people get used to you; they see you on a daily basis ... Daily visibility - you become known and seen. (Respondent 4, Female, Volunteer)

\section{Volunteer opportunities}

The hospital being studied took pride in being seen as a place of opportunity. However, a volunteer coordinator was deemed essential as well as the funding for such a post to make the programme viable and sustainable. Management bought into the volunteer programme, which contributed to the success thereof. Experienced volunteers were used to train new recruits.

\section{The comments included:}

I think one of the great successes is that management bought into it. (Respondent 1, Female, Hospital management)

$\mathrm{He}$ is so valuable for me, because now if we want to place volunteers, we place them with him and he trains them because he knows what it was like when he was a volunteer. (Respondent 1, Female, Hospital management)

The hospital is now a place of opportunity. (Focus group discussion)

It was pointed out to us that it was a program where no promises are made. It is a voluntary service, but it can lead to a permanent position at the hospital. (Respondent 3, Male, Volunteer)

People went from volunteering to get jobs in different places ... Gainful employment and we are very proud of that. (Respondent 5, Male, Hospital Management)

In some cases, permanent staff took a back seat when volunteers were deployed to a department. Tight control of work allocation and the management of roles, responsibilities and relationships between volunteers and hospital staff were required, as evidenced in the comment below:

They will stand talking to each other, and the volunteer will do the work and that is a challenge for their manager, because that manager needs to manage their people together with the volunteers, but sometimes is does not work so well. (Respondent 1, Female, Hospital management)

\section{Discussion}

Where Blanchard (2006, p. 36) found that reputational gains and experience were not significant factors in volunteer motivation, this study found the contrary. It could be argued that in the South African context, with unemployment rates of around $25 \%$ and youth unemployment over $60 \%$ (Statistics South Africa, 2015), such motives are more critical. Respondents reported having a sense of belonging and daily importance in their work as volunteers. Connors (2011) acknowledges that volunteer and staff relations remain critical and complex and calls for adequate communication between these parties as well as orientation and training of volunteers. Skill development to gain experience towards paid employment was a significant factor in the motivations of respondents. The hospital management also felt that training and experience had the benefit to the volunteer towards possible employment and to the hospital should they recruit the volunteer, as they were 'pre-trained' for the job.

Motivation is a concept used to describe the intrinsic responses sustained by human needs, which in turn stimulate people to action in order to seek and achieve goals to satisfy those needs. The data that emerged from this study were well aligned to the Maslow's (1954) hierarchy of needs and confirmed that needs are continuous and that volunteers are more enthusiastically motivated by what they are seeking. No matter what they have achieved in terms of volunteerism; lower order needs such as a sustainable income will always be the focus and energy (Jooste, 2009, pp. 69-71).

Maslow's theory of motivation serves the purpose of explaining the volunteerism phenomenon and was used in the inductive process of building from the data to themes. The data collected from the volunteer participants in terms of motive were applied to Maslow's motivational theory and tabulated in Table 1.

From the themes which emerged and the literature (Botma, Greeff, Mulaudzi \& Wright, 2010, p. 199), the theory could also be applied to the motivation of the hospital with regard to the volunteer programme and is depicted in Table 2.

TABLE 1: Maslow's motivational theory as applied to the volunteers experiences.

\begin{tabular}{ll}
\hline Volunteer needs & Volunteer rewards \\
\hline Self-actualisation & $\begin{array}{l}\text { Maximising potential and growth opportunities are offered in } \\
\text { terms of choice of placement, relevant training and assistance } \\
\text { with job application processes. }\end{array}$ \\
$\begin{array}{l}\text { Esteem or status } \\
\text { needs }\end{array}$ & $\begin{array}{l}\text { Volunteers are known in the hospital, which makes them feel } \\
\text { good about themselves thus boosting self-esteem. They are } \\
\text { valued by staff, given responsibility and can achieve } \\
\text { certificates for training. }\end{array}$ \\
$\begin{array}{l}\text { Social or belonging } \\
\text { needs }\end{array}$ & $\begin{array}{l}\text { Volunteers work in groups or are placed in teams, included in } \\
\text { training and develop relationships with fellow volunteers and } \\
\text { staff. }\end{array}$ \\
$\begin{array}{l}\text { Safety or security } \\
\text { needs }\end{array}$ & $\begin{array}{l}\text { An ordered, safe working environment is provided and access } \\
\text { to workplace injury services. }\end{array}$ \\
$\begin{array}{l}\text { Physiological or } \\
\text { survival needs }\end{array}$ & $\begin{array}{l}\text { Experience and skill can lead to wage-earning to pay for basic } \\
\text { needs. }\end{array}$ \\
\hline
\end{tabular}

TABLE 2: Maslow's motivational theory as applied to the hospital's perspective. Hospital needs Hospital rewards

Self-actualisation Self-actualisation is achieved by the hospital by affording elf community it serves.

Esteem or status The hospital gains esteem by being seen as a place of needs opportunity.

Social or belonging The hospital expands its engagement with the community by needs embracing the volunteers from the community.

Safety or security Patient safety and quality are enhanced by essential support needs services being supplemented by volunteers.

Survival or survival The cost-benefit analysis indicates that the man-hours gained needs from volunteers impact well on the bottom line. 
From an implementation of a volunteer programme perspective, the interviews with management illuminated the risk management requirements. Wyngaard (2012, p. 31) warns about vicarious liability and volunteers. This means that the organisation could be held liable for unlawful conduct of volunteers. Connors (2011) calls for courses in volunteer resource management at facilities and dedicated attention to volunteerism policy development. In this study, a volunteer policy was drawn up and overseen by the chief executive officer (CEO).

Documentation on application to volunteer initially included declarations on criminal records. A subsequent innovation under consideration is to get police criminal record clearance certificates for volunteers, but had not been implemented until the end of this study. However, a code of conduct for volunteers is a recommendation of this study, as well as a rigorous application process. Hotchkiss et al. (2014, p. 15) concur that health care organisations need to carefully screen volunteers prior to selection to maximise the quality benefits.

Constant redefining of risk management boundaries when it comes to having volunteers in a health setting makes for good governance. Risk assessment leads to appropriate volunteer assignments, identification of the necessary qualifications to fill those roles, targeted recruitment for those skills, proper screening, solid orientation and training and monitoring (Ellis, 2012). In this study setting, the volunteers are managed by a coordinator, who in turn is managed by a senior manager in the hospital. The CEO oversees the programme and reports to the Hospital Facility Board, which would fund the costs of the programme, appoint the coordinator and act on behalf of the public should any complaints or concerns be raised about the volunteer programme.

Volunteerism is important in the management of health care facilities as it allows the organisation to substitute volunteers for paid staff, offers significant cost savings to hospitals and is likely to impact on quality indicators such as patient satisfaction and safety (Hotchkiss et al., 2014, p. 2). More research is required to measure the cost-benefit ratio and impact on organisational performance. This study found a definite benefit in volunteers bolstering human capital and an impact in the health care organisational performance through contributions made by volunteers in many different settings in the hospital. Health care organisations should assess which additional activities, duties and responsibilities could be assumed by volunteers.

\section{Recommendations}

The findings of this study could serve to inform health service practice management of recommendations for hospital volunteer programmes. Initially, the hospital needs to secure seed funding to appoint a coordinator and for the start-up equipment. Hospital management needs to develop a risk management strategy. Risk management strategies should include careful selection of volunteers and character interrogation, such as criminal record clearance to prevent vicarious liability.
The volunteers need to be integrated into the orientation and induction processes, as well as staff training opportunities. By the same token, volunteers should take advantage of training opportunities afforded to them. Volunteers should have some choice of the section they want to work in to ensure a good fit.

However, the relationships between hospital staff and volunteers need to be clarified. In most cases, the relationship between hospital staff and volunteers should be actively managed. Exploitation of volunteers by permanent hospital staff must be prevented. Volunteers need some initial guidance on how to engage in various departments and with hospital staff. They need to develop resilience for some of the relationship challenges between volunteers and hospital staff. Although the volunteering holds distinct benefit in terms of self-development, self-esteem and self-actualisation, perseverance is required on the part of the volunteer. Volunteers need to be acknowledged and valued for the contribution they make to the health care environment.

\section{Conclusion}

Hospital volunteerism promises to be a quid pro quo, or something for something, intervention which benefits both hospital and volunteer. The hospital benefits in efficiency gains, development of local community members and in recruitment of potential future staff members. Volunteers benefit, by giving of their time, in learning new skills, gaining experience and belonging to a setting where they have a daily purpose and are valued. Provided risk is managed and minimised, the promise of possibility permeates to both volunteer and hospital facility.

\section{Acknowledgements}

This study has been supported and is funded by Stellenbosch University, Fund for Innovation and Research in Rural Health (FIRRH).

\section{Competing interests}

The authors declare that they have no financial or personal relationships that may have inappropriately influenced them in writing this article.

\section{Authors' contributions}

G.M.L. was responsible for the research proposal, ethics applications, data collection and data analysis of this article. D.K.D-F. carried out the literature review and performed the data analysis triangulation.

\section{References}

Aragaki, M., Saito, T., Takahashi, M., \& Kai, I. (2007). Hospital volunteer's role and accident prevention systems. A nationwide survey of Japanese hospitals. Health Services Management Research, 20,220-226. https://doi.org/10.1258/095148407782219021

Blanchard, J.A. (2006). Hospital volunteers: A qualitative study of motivation. The International Journal of Volunteers Administration, 14(2), 31-40.

Botma, Y., Greeff, M., Malaudzi, F., \& Wright, S. (2010). Research in health sciences. Cape Town: Pearson.

Bowling, A. (2009). Research methods in health. Berkshire: Open University Press. 
Connors, T. (2011). The volunteer management handbook: Leadership strategies for success (2nd ed.). Hoboken, NJ: Wiley.

Ellis, S. (2012). Common sense and volunteer involvement. Retrieved May 14, 2017 from https://www.energizeinc.com/hot-topics/2012/april

Handy, F., Mook, L., \& Quarter, J. (2008). The inter changeability of paid staff and volunteers in nonprofit organizations. Nonprofit and Volunteer Sector Quarterly, 37(1), 76-92. https://doi.org/10.1177/0899764007303528

Handy, F., \& Srinivasan, N. (2004). Valuing volunteers: An economic evaluation of the net benefits of hospital volunteers. Nonprofit and Voluntary Sector Quarterly, 33, 28-54. https://doi.org/10.1177/0899764003260961

Hotchkiss, R.B., Fottler, M.D., \& Unruh, L. (2009). Valuing volunteers: The impact of volunteerism on hospital performance. Health Care Management Review, 34(2), 119-128.

Hotchkiss, R.B., Unruh, L., \& Fottler, M.D. (2014). The role, measurement, and impact of volunteerism in hospitals. Nonprofit and Voluntary Sector Quarterly, 1-18. https://doi.org/10.1097/HMR.0b013e31819e919a

Jones, H. (2004). Volunteering for health. Wales Council for Voluntary Action, Welsh Assembly Government. Retrieved May 17, 2017, from http://www.wales.nhs.uk/ documents/volunteering-for-health-report-e.pdf
Jooste, K. (Ed.). (2009). Leadership in health services management (2nd ed.). Landsdowne: Juta.

Maslow, A.H. (1954). Motivation and personality. New York: Harper \& Row.

Maxwell, J.A. (2012). A realist approach for qualitative research. Thousand Oaks, CA Sage.

Penner, L.A. (2002). Dispositional and organizational influences on sustained volunteerism: An interactionist perspective. Journal of Social Issues, 58, 448. https://doi.org/10.1111/1540-4560.00270

Prabhu, V.R., Hanley, A., \& Kearney, S. (2008). Evaluation of a hospital volunteer programme in rural Australia. Australian Health Review, 32(2), 265-269. https:// doi.org/10.1071/AH080265

Ross, T. (2012). A survival guide for health research methods. Berkshire: Open University Press.

Statistics South Africa. (2015). Quarterly labour force survey: Quarter 2. Pretoria: South African Government.

Wyngaard, R. (2012). A practical legal guide to South African volunteers. Cape Town: Ricardo Wyngaard Attorneys. 